\title{
Mapping and assessing spatial multiscale variations of birds associated with urban environments in metropolitan Taipei, Taiwan
}

\author{
Yun-Bin Lin • Yu-Pin Lin • Wei-Ta Fang
}

Received: 17 March 2007 / Accepted: 30 October 2007 / Published online: 12 January 2008

(C) Springer Science + Business Media B.V. 2007

\begin{abstract}
Environmental change can be monitored and assessed by analyzing changes in bird populations. This study employed multivariate factorial kriging (MFK) to determine the multiscale changes in the distribution of five commonly observed bird species to urban environmental change. Areas of metropolitan Taipei were analyzed to determine the extent and effect of land cover. A digital elevation model and normalized difference vegetation index were also constructed. Spatial patterns of variation in bird populations were analyzed by MFK at a regional scale $(16 \mathrm{~km})$ and local scale $(2 \mathrm{~km})$. Comparison of MFK results with those obtained by conventional principal component analysis (PCA) and correspondence analysis (CA) showed that the conventional PCA results were comparable to the MFK results at the local scale, and the CA results were comparable to
\end{abstract}

Y.-B. Lin

Department of Recreation and Health-Care Management, ChiaNan University of Pharmacy \& Science,

Rende Shiang,

Tainan County 71710, Taiwan, Republic of China

Y.-P. Lin $(\bowtie)$

Department of Bioenvironmental Systems Engineering, National Taiwan University,

Taipei 10617, Taiwan, Republic of China

e-mail: yplin@ntu.edu.tw

W.-T. Fang

Department of Landscape Architecture,

Tunghai University,

Taichung 40704, Taiwan, Republic of China
MFK results at the regional scale. The MFK indicated that local-scale variation accounts for a larger proportion of the total variation than regional-scale variation, and local-scale variation is affected by more factors than regional scale variation. The MFK results also showed that heterogeneous elevation exerts a geographical influence on bird populations at the regional scale whereas the land cover of urban meadows in densely populated urban areas of Taipei exerts a local influence. The suburban trees and meadows in belt regions between suburbs have local and regional influences on bird distributions, respectively. The spatial patterns of bird populations in response to urban environments can be adequately explained by their diet categories and body sizes. The MFK, which simultaneously provides descriptive variations and spatial patterns in species at determinate scales, facilitates environmental interpretations of ordination results and identification of determinants for conservation efforts at multiple scales.

Keywords Multivariate factorial kriging .

Principal component analysis .

Correspondence analysis .

Species-environment relationships · Land cover .

DEM $\cdot$ NDVI

\section{Introduction}

Birds are considered excellent indicators of environmental changes as birds are highly visible and very 
sensitive to changes in habitat structure and composition (Savard et al. 2000). In community-level studies, influences of environmental mosaics on bird communities are driven by landscape evolution (Marzluff et al. 2001; Wiens 1989). Landscape mosaics can be generated by multiple disturbances that affect the substrate, physical environment and resource availability. These disturbances typically dominate the creation of complex landscape patterns or change land surfaces at multiple scales in disturbed regimes (Turner et al. 2001). Consequently, analysis of bird community variations that interact with a landscape mosaic should be spatially explicit and multi-scale. Moreover, the scale of landscape mosaics relevant to bird communities is an important determinant in how questions are addressed, procedures are followed, observations are acquired and results are interpreted (Hostetler and Holling 2000; Levin 1992; Wiens 1989).

In urban areas, habitat fragmentation generated by humans has produced nested patterns in species distributions at multiple scales (Fernández-Juricic 2002; Hostetler 1999; Savard et al. 2000). GithaigaMwicigi et al. (2002) established a conceptual model that explains multi-scale variations in bird distributions that are influenced by multiscale environmental variables. Moreover, studies focused on habitat selection have suggested that the utilization of spatial structures as habitat is decided via a nested set of hierarchical selections made by birds from large scales to small scales (Hostetler and Holling 2000). Considerable attention has been given to evaluating multi-scale species-environment relationships and conducting conservation efforts in relation to spatial scales (Cushman and McGarigal 2004; Thogmartin et al. 2004).

Wiens et al. (2002) suggested that effective conservation management should be based on the identification of functional species groups that respond similarly to landscape structures. Ordination, which is utilized to assess gradients in species composition, is the primary approach employed for determining variation in a bird community in reduced principal dimensions (Legendre and Legendre 1998; Wagner 2004). Thus, ordination has been widely adopted for interpretations of avian responses to environments (e.g., Bennett et al. 2004; Chase et al. 2000). Since only the outcomes of variations in an avian community can be observed in the field, separating total variation into variation components at different scales is essential for clarifying causations of variations at different scales (Lin et al. 2006). Numerous studies have investigated multi-scale ordination (e.g., Brennan and Schnell 2005; Drapeau et al. 2000; Melles et al. 2003; ver Hoef and GlennLewin 1989), based on an awareness of the inherent spatial variability in the structure of avian communities. However, conventional ordination methods, such as principal component analysis (PCA), redundancy analysis (RDA), correspondence analysis (CA), and canonical correspondence analysis (CCA), which do not use spatial information, are unsuited to the spatial analysis paradigm (Wagner 2004).

Spatial information can be acquired from variography in geosatistics (Goovaerts 1997; Legendre and Fortin 1989; Wagner and Fortin 2005). Ecologists and scientists have become increasingly sophisticated in quantifying and including spatial components via geostatistics (Aubry and Debouzie 2001; Dale et al. 2002; Diniz-Filho et al. 2003; Dungan et al. 2002; Fortin 1999). Diniz-Filho and Bini (2005) used geostatistical methods to map spatial patterns of ordination results derived using conventional PCA. Geostatistics has been applied for multi-scale ordination by Couteron and Ollier (2005), Wagner (2004), and Wagner and Fortin (2005) based on the scheme proposed by ver Hoef and Glenn-Lewin (1989). As an alternative method, the multivariate factorial kriging method (MFK) was adopted to model and analyze multi-scale variations in a plant community (Maestre 2005; Nanos et al. 2005) and were applied to characterize the multiscale defoliation caused by spruce budworm (Bellier et al. 2007). The MFK approach has recently been widely used in many fields, including seismology (Lin et al. 2004), geochemistry (Bourennane et al. 2003; Reis et al. 2003), remote sensing (Goovaerts et al. 2005), and contamination assessment (Lin 2002; Lin et al. 2006). Bellier et al. (2007) indicated MFK is suitable to analyze explicitly the spatial patterns of species in relation to environmental variation, and to provide more hypotheses in order to draw inferences on how organisms respond to the heterogeneity of their environment at multiple scales.

This study carried out a multi-scale ordination using the MFK approach. Three environmental variables generated from remote sensing data, including land cover, the digital elevation model (DEM), and the 
normalized difference vegetation index (NDVI), were utilized for environmental interpretations of ordination results. Debinski et al. (1999) and Luoto et al. (2002) indicated that remote sensing data rather than data gathered from field-intensive methods for constructing relationships between species and habitats should be applied to species that are sufficiently common and/or habitat-specific to identify significant relationships between species and environments. Therefore, this study focused on five commonly observed urban species: the Pacific Swallow, Light-vented Bulbul, Japanese White-eye, Eurasian Tree Sparrow and Spotted Dove. Ordination results obtained using MFK, conventional PCA and CA were compared and discussed. Ordination results were interpreted in relation to environmental variables, and environmental interpretations were further related to avian physiological habits and characteristics. The applications of MFK for conservation efforts were also illustrated.

\section{Methods}

Conventional ordination methods

The principal component analysis (PCA) was used to quantify patterns of covarying species within communities (Grossman et al. 1991). The principal components (PCs) can reflect main trends of all species with respect to some determinate factors (Legendre and Legendre 1998). Moreover, instead of representing physical measures, PCs can only be further correlated with environment variables to reveal the possible representations for factors. The CA is similar with the conventional PCA, except it determines the $\chi^{2}$ distance rather than the Euclidean distance between sample variables (Legendre and Legendre 1998). Therefore, the observed matrix should be transformed prior before being substituted into the PCA algorithm

$\widetilde{A_{i j}}=\operatorname{diag}\left[\left(A_{i \bullet}\right)^{-0.5}\right] \times A_{i j} \times \operatorname{diag}\left[\left(A_{\bullet j}\right)^{-0.5}\right]$,

Where $A_{i j}$ and $\widetilde{A_{i j}}$ are the original and transformed sample matrices of species $j$ at sample site $i$, respectively; diag [ ] represents a diagonal matrix; $A_{i} \bullet=\sum_{j=1}^{Q} A_{i j}, Q$ is the total number of species; $A_{\bullet j}=$ $\sum_{i=1}^{P} A_{i j}$
The CA and conventional PCA results can be presented by diagramming species in a correlation circle against the first two principal component axes to present the correlations between species and principal components (PCs). The CA and conventional PCA also computes PCs at each sample site based on variations in birds observed at sample sites. The $n$th principal component $X_{n}$ at any unsampled location $\mathbf{u}^{\prime}$ can be interpolated by ${ }_{p}$ ordinary kriging with the relationship of $X_{n}\left(\mathbf{u}^{\prime}\right)=\sum_{\alpha=1} \varsigma_{\alpha n}\left(\mathbf{u}^{\prime}\right) X_{n}\left(\mathbf{u}_{\alpha}\right)$, and the weight $\varsigma_{\alpha n}\left(\mathbf{u}^{\prime}\right)$ is determined from

$$
\left\{\begin{array}{c}
\sum_{\beta=1}^{P} \varsigma_{\alpha n}\left(\mathbf{u}^{\prime}\right) \overline{\gamma_{n}\left(\mathbf{u}_{\alpha}-\mathbf{u}_{\beta}\right)}=\overline{\gamma_{n}\left(\mathbf{u}_{\alpha}-\mathbf{u}^{\prime}\right)} \quad \alpha=1, \ldots, P \\
\sum_{\alpha=1}^{P} \varsigma_{\alpha n}\left(\mathbf{u}^{\prime}\right)=1
\end{array}\right.
$$

where $P$ is the total number of sample sites, and $\overline{\gamma_{n}}$ is the auto-semivariogram model of the $n$th principal component $X_{n}$ (Goovaerts 1997). The relationships between PCs and environmental variables can be identified using a plot drawn against the categorized environmental variables and mean values of interpolated PCs in each category to reveal PC trends with variations in environmental variables.

\section{Multivariate factorial kriging}

The MFK approach has three componential steps: determining the linear model of co-regionalization (LMC), PCA, and mapping (Castrignanò et al. 2000). In MFK, auto- and cross-experimental semivariograms are generated and then modeled using the linear combination of basic permissible models with different ranges. The modeling procedure, which is called co-regionalization in a multivariate case, generates co-regionalization matrices at multiple scales. The preliminary co-regionalized matrices can be acquired by minimizing the value of the indicative goodness-of-fit (IGF) when fitting each experimental semivariogram with semivariogram models (see Pannatier (1996) for details). However, the coregionalization matrix must be positively semidefinite (Goovaerts 1997). Goulard and Voltz (1992) proposed an iterative algorithm for determining the LMC that minimizes the weighted sum of squared differences between experimental semivariograms and semivariogram models, and to retain a positive semi- 
definition for the co-regionalization matrix. The resulting co-regionalized matrices at different scales are subsequently applied to the PCA to compute PCs at different scales, i.e., regionalized factors (RFs) (see Goovaerts (1997) for details).

The MFK results are presented by diagramming species in correlation circles against the first two regionalized factor axes to present the correlations between species and RFs at different scales. The MFK approach computes RFs for each sample site at multiple scales according to the multi-scale variation structure of birds observed at sample sites. The regionalized factor $Y_{k}^{l}$ of scale $l$ at any unsampled location $\mathbf{u}^{\prime}$ can be interpolated by factorial co-kriging with the relationship of $Y_{k}^{l}\left(\mathbf{u}^{\prime}\right)=$ $\sum_{i=1}^{I} \sum_{\alpha_{i}=1}^{P} \lambda_{\alpha_{i} k}^{l}\left(\mathbf{u}^{\prime}\right) Z_{i}\left(\mathbf{u}_{\alpha_{i}}\right)$, and weight $\lambda_{\alpha_{i} k}^{l}$ is calculated from

$$
\left\{\begin{array}{cc}
\sum_{j=1}^{I} \sum_{\beta j=1}^{P} \lambda_{\alpha_{i k}}^{l}\left(\mathbf{u}^{\prime}\right) \overline{\gamma_{i j}\left(\mathbf{u}_{\alpha i}-\mathbf{u}_{\beta j}\right)}=a_{i k}^{l} g^{l}\left(\mathbf{u}_{\alpha_{i}}-\mathbf{u}^{\prime}\right) & \alpha_{i}=1, \ldots, P i=1, \ldots, I \\
\sum_{\alpha_{i}=1}^{P} \lambda_{\alpha_{i} k}^{l}\left(\mathbf{u}^{\prime}\right)=0 & i=1, \ldots, I
\end{array}\right.
$$

where $I$ is the total number of scales; $g^{l}$ is the basic permissible model at scale $l ; \overline{\gamma_{i j}}$ is the cross-semivariogram model of species $i$ and $j$ (Goovaerts 1997). The relationships between RFs and environmental variables can be identified using the plot drawn against the categorized environmental variables and mean values of interpolated RFs in each category, revealing the RF trends for variations in environmental variables.

\section{Materials}

Study area

Taipei City, the capital of Taiwan, is located in northern Taiwan (longitude $25^{\circ} 03^{\prime} \mathrm{N}$ and latitude $121^{\circ} 30^{\prime} \mathrm{E}$ ), and occupies the eastern part of the Taipei Basin, that is bounded, moving clockwise from north to south, by Mt. Datun (maximum elevation 1,092 m), Mt. CiSing (1,120 m), Mt. WuZhi (699 m), Mt. NanKang (340 m), and Mt. ErGe (678 m). The western boundary of the city is the DanShui River. And the JiLong River, which flows from east to west through the city, discharges into the DanShui River.
Taipei City has a typical subtropical monsoon climate (Kuo and Young 1981). The city covers $271.8 \mathrm{~km}^{2}$. Due to the laws and regulations limiting land exploitation, anthropic activities mainly occur on plains at elevations below $100 \mathrm{~m}$, which is regarded as the densely populated part of Taipei in this study (Fig. 1).

\section{Avian sampling}

Avian data of five species - the Pacific Swallow, Light-vented Bulbul, Japanese White-eye, Eurasian Tree Sparrow and Spotted Dove - was collected from the Taiwan Bird Record Database of the Taiwan Wild Bird Federation in Taipei City during 1998. The Taiwan Bird Record database is constructed according to reports from wild bird societies of individual counties, and each wild bird society has volunteers who are trained in observing birds and report their sightings during bird counts. The observers randomly selected the observation spot and recorded birds seen or heard within a $200 \mathrm{~m}$ radius of each spot. The avian dataset used in this study was collected from 39 sample sites (Fig. 1). Table 1 lists the scientific name, common name and descriptive statistics of the avian census data. The distribution of the Eurasian Tree Sparrow has the largest skewness and kurtosis, and the Pacific Swallow has the smallest skewness and kurtosis. The Japanese White-eye and Light-vented Bulbul are omnivores with frugivorous habits in branches. The Pacific Swallow is an aerial insectivore, while the Spotted Dove and Eurasian Tree Sparrow are omnivores with granivorous habits on the ground. The average adult body lengths are as follows: $11 \mathrm{~cm}$, Japanese White-eye; $13 \mathrm{~cm}$, Pacific Swallow; $14 \mathrm{~cm}$, Eurasian Tree Sparrow; $19 \mathrm{~cm}$, Light-vented Bulbul; and, $30 \mathrm{~cm}$, Spotted Dove (Chang 1985; Fang et al. 2005).

\section{Environmental variables}

Habitat heterogeneity was determined based on landcover classes and elevations of sample sites. The cloud-free SPOT HRV image on July 16, 1998, was adopted for land-cover classifications. Land cover was divided into 12 classes using ERDAS IMAGINE software (Leica Geosystems 2003) with the supervised classification (maximum likelihood) and fuzzy convolution operations (Fig. 2a). The ground-true 
Fig. 1 The geography, infrastructures, and sample sites in Taipei City

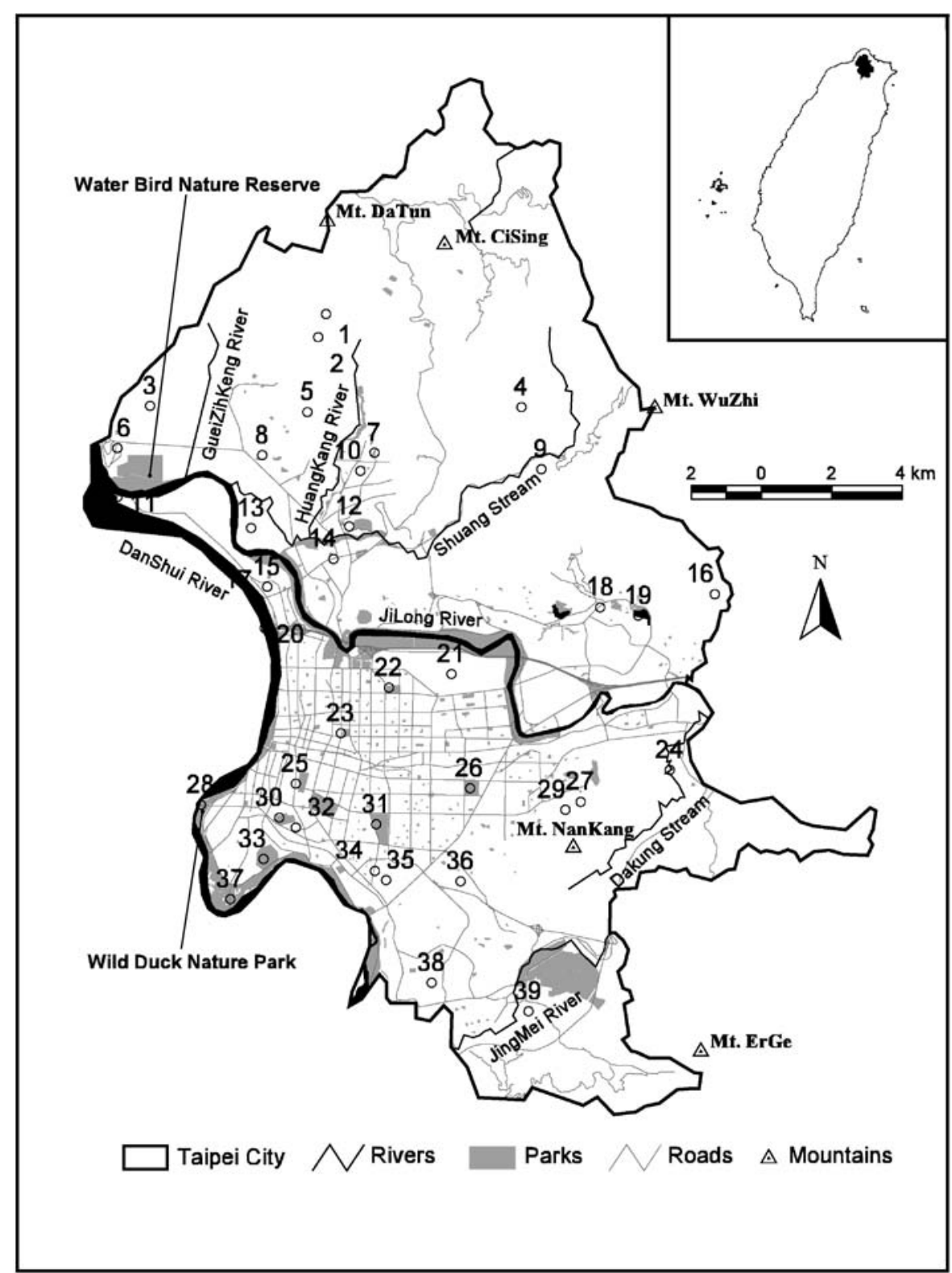

data was obtained from black-and-white aerial photographs at a scale of $1 / 25,000$. Accuracy totals was $89.1 \%$, whereas the Kappa coefficient was 0.87 . The DEM on a $40 \times 40 \mathrm{~m}$ rectangular grid was used to represent elevation heterogeneity of the study area (Fig. 2b). The NDVI has been used extensively to monitor the vigor of plants and as measure of canopy density (Viedma et al. 1997). The NDVI, which is associated with total plant biomass and primary productivity (Box et al. 1989; Tucker et al. 1985), was calculated by dividing the difference between the reflectance readings in the near-infrared (NIR) and visible-red (RED) light spectrums by the sum of both readings (Jensen 1996):

$\mathrm{NDVI}=\frac{\mathrm{NIR}-\mathrm{RED}}{\mathrm{NIR}+\mathrm{RED}}$,

where the NDVI values range from -1 to +1 . The high NDVI value represents the large amount of highphotosynthesizing vegetation (Bailey et al. 2004; Pettorelli et al. 2005). The NDVI image was generated from a cloud-free image of SPOT HRV with the resolution of $12.5 \mathrm{~m}$ on July 16,1998 (Fig. 2c). 
Table 1 Scientific name, alias, and descriptive statistics for each species

\begin{tabular}{|c|c|c|c|c|c|c|c|c|c|c|c|}
\hline \multicolumn{2}{|l|}{ Species } & \multicolumn{10}{|c|}{ Descriptive statistics* } \\
\hline Scientific name & Alias & $N$ & $A$ & $\mathrm{Sd}$ & $S^{\mathrm{a}}$ & $K^{\mathrm{a}}$ & $\operatorname{Max}$ & 75 & 50 & 25 & Min \\
\hline \multicolumn{12}{|l|}{ Endemic subspecies } \\
\hline Streptopelia chinensis (S. c. formosae) & Spotted Dove & 27 & 3.80 & 3.09 & 1.59 & 2.49 & 13.40 & 4.44 & 3.00 & 1.69 & 1.00 \\
\hline Pycnonotus sinensis (P. s. formosae) & Light-vented Bulbul & 38 & 22.51 & 16.33 & 1.39 & 2.26 & 77.00 & 30.00 & 18.67 & 12.00 & 1.00 \\
\hline \multicolumn{12}{|l|}{ Common species } \\
\hline Hirundo tahitica (H. t. namiyei) & Pacific Swallow & 28 & 9.83 & 8.76 & 1.17 & 0.42 & 30.00 & 14.35 & 6.00 & 3.09 & 1.00 \\
\hline Zosterops japonicus (Z. j. simplex) & Japanese White-eye & 33 & 23.39 & 22.99 & 2.28 & 5.98 & 100.00 & 28.44 & 20.00 & 9.00 & 1.50 \\
\hline Passer montanus (P. s. saturatus) & Eurasian Tree Sparrow & 37 & 56.51 & 70.73 & 3.40 & 15.28 & 400.00 & 79.00 & 30.00 & 15.00 & 1.00 \\
\hline
\end{tabular}

* $N$ sampling numbers; $A$ average; $S d$ standard deviation; $S$ skewness; $K$ kurtosis; Max maximum; Min minimum; 75, 50, 25: percentile

${ }^{\text {a }}$ Zero for the normal distribution

\section{Results}

Multi-scale determination by variography

To prevent estimation bias, census data were normalized with zero mean and unit variance for each species before adoption for determining experimental semivariograms. Auto- and cross-experimental semivariograms were determined using VARIOWIN software (Pannatier 1996) (Fig. 3). Wiens (1989) and Lin et al. (2007) indicated that the spatial pattern of richness in bird species frequently involves a combination of large-scale biogeographical variation and fine-scale ecological variation. Based on earlier studies of large-scale environmental effects on bird species in Taiwan (Ding et al. 2005; Lee et al. 2004), the positive effects of elevation and NDVI are observable at elevations under $2,000 \mathrm{~m}$. Therefore, the determined semivariance was separated horizontally into two scales, local and regional, to examine proportions of variation at different scales. According to IGF, the auto- and cross-experimental semivariograms in this study were initially and most appropriately modeled using the sum of the following three models: the nugget-effect term, the spherical model with a range of $2 \mathrm{~km}$ denominated as the local scale and the Gaussian model with a range of $16 \mathrm{~km}$ denominated as the regional scale as follows

$$
\begin{aligned}
\gamma_{i j}(h)= & b_{i j}^{0}+b_{i j}^{1}\left(1.5 \frac{|h|}{2,000}-0.5\left(\frac{|h|}{2,000}\right)^{3}\right) \\
& +b_{i j}^{2}\left(1-e^{\frac{-3|h|^{2}}{16,000^{2}}}\right),
\end{aligned}
$$

where $\gamma_{i j}(h)=b_{i j}^{0}+b_{i j}^{1}+b_{i j}^{2}\left(1-e^{\frac{-3|h|^{2}}{16,000^{2}}}\right)$ for $h \geq$ $2,000 \mathrm{~m} ; i$ and $j$ represent species, $i, j=1, \ldots, 5 ; b_{i j}^{0}$ is the nugget effect; $b_{i j}^{1}$ is the sill of spherical structure; $b_{i j}^{2}$ is the sill of Gaussian structure; $h$ is the lag distance between sample sites. The regional scale of $16 \mathrm{~km}$ is consistent with the scale developed in an earlier study by Lin et al. (2007) for analyzing spatial patterns of bird diversity in the Taipei Basin. The LMC was determined using the method proposed by Goulard and Voltz (1992). Goovaerts (1997) suggested that the LMC can be achieved at the expense of large deviations between the auto-experimental semivariograms and semivariogram models. Therefore, the autosemivariogram model results were carefully reviewed, and no deviations were observed (Fig. 3).

\section{Ordinations and mappings}

For CA and conventional PCA without considering spatial information, the first two PCs, PC1 and PC2, explained 53.8 and $60.4 \%$ of total variation, respectively. The CA results for the Pacific Swallow, Light-vented Bulbul and Spotted Dove positively correlated with PC1 whereas those for the Japanese White-eye negatively correlated with PC1. The Pacific Swallow positively correlated with PC2 whereas the Eurasian Tree Sparrow negatively correlated with PC2 (Fig. 4a). The PCA results for each of the five species positively correlated with PC1. The Japanese White-eye results positively correlated with PC2 whereas the Pacific Swallow results negatively correlated with PC2 (Fig. 4b).

In MFK, the nugget effect, which results from either micro-scale variation or measurement errors, 
Fig. 2 The environmental variables used in this study: a land cover, b DEM, and $\mathbf{c}$ NDVI
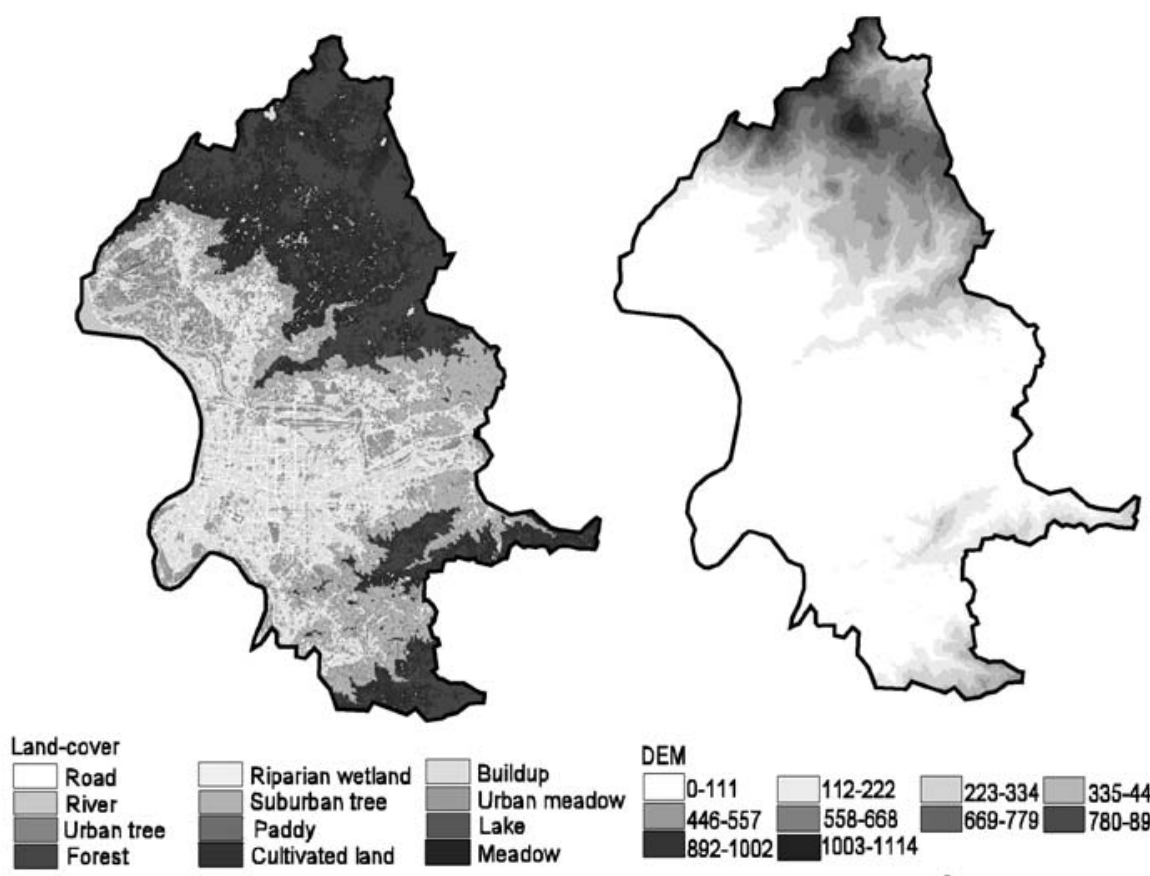

a

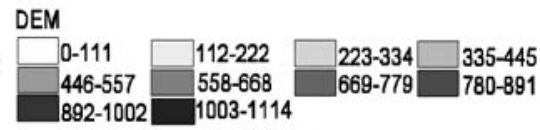

b

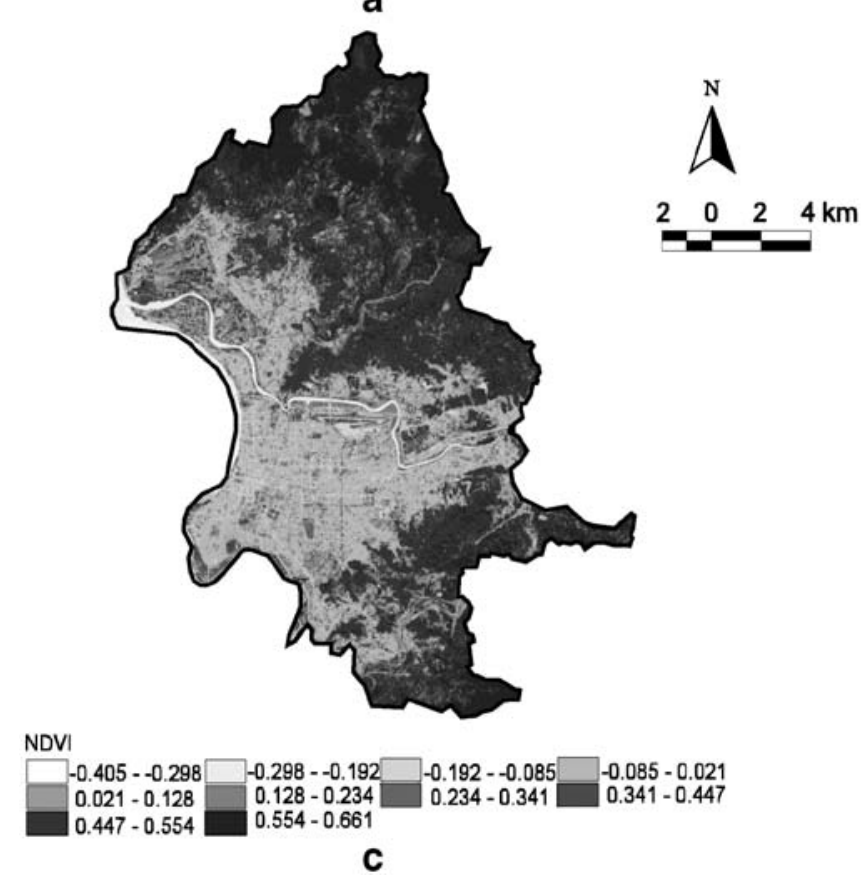

explained $26.7 \%$ of total variation. The remaining total variation generated at the local scale was $81.2 \%$, and that generated at the regional scale was $18.8 \%$. The first two RFs, RF1 and RF2, at the regional scale explained $96.5 \%$ of regional-scale variation whereas RF1 and RF2 at the local scale explained $85.6 \%$ of local-scale variation. At the regional scale, the
Japanese White-eye and Pacific Swallow were positively correlated with RF1. The Light-vented Bulbul and Spotted Dove were positively correlated with RF2 whereas the Eurasian Tree Sparrow was negatively correlated with RF2 (Fig 4c). At the local scale, each of the five species was positively correlated with RF1. The Pacific Swallow and Eurasian Tree Sparrow 


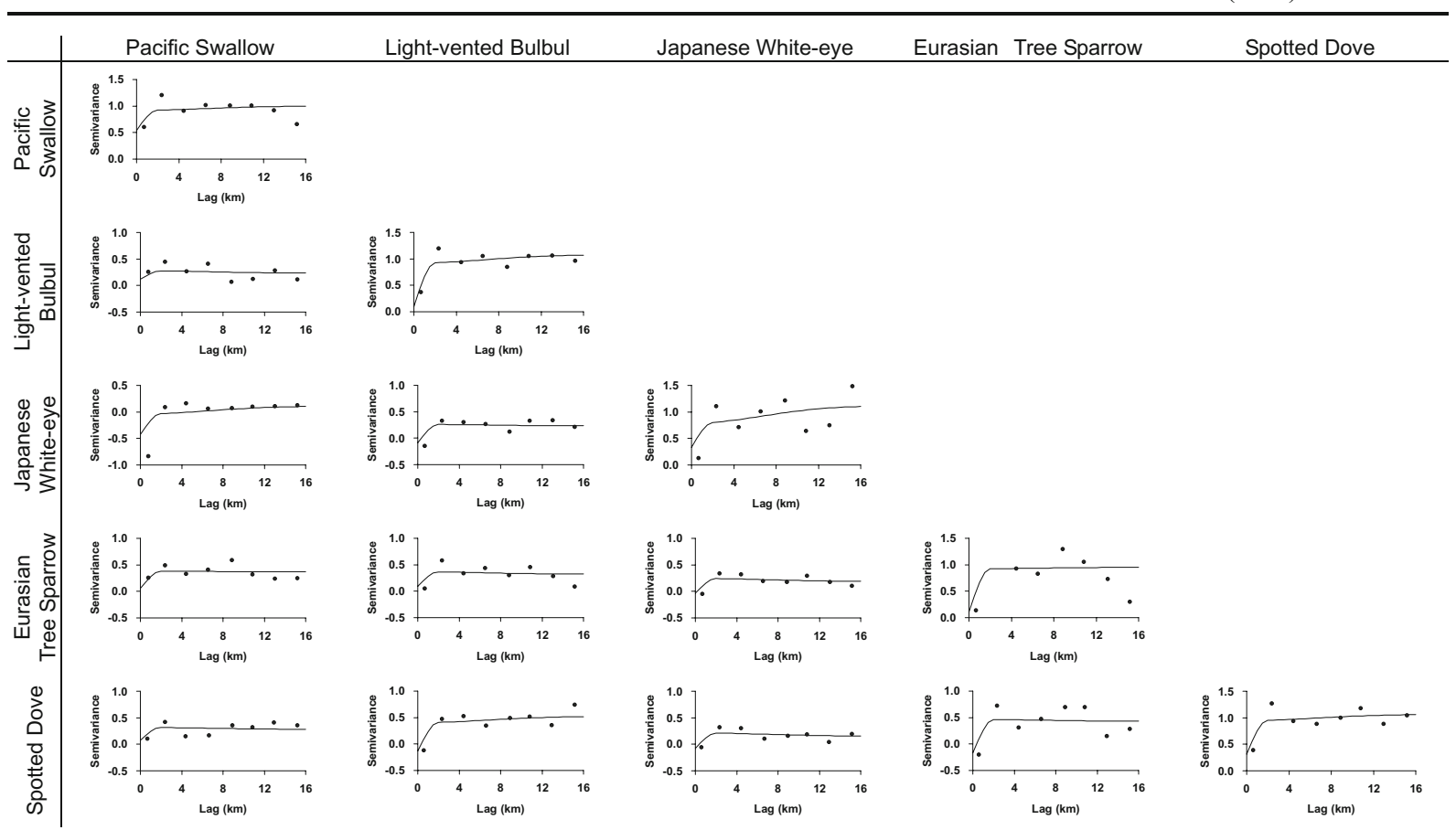

Fig. 3 The auto- and cross-experimental semivariograms (solid circles), and their semivariogram models (solid lines) drawn in accordance with LMC results

were negatively correlated with RF2 whereas the Light-vented Bulbul was positively correlated with RF2 (Fig. 4d).

Except the Pacific Swallow, comparisons between correlation circles for CA and MFK at the regional scale showed that negative PC1 was related to positive RF1 while PC2 and RF2 were positively related (Fig. 4a,c). The correlation circles for MFK at two scales exhibited two spatial patterns (Fig. 4c,d), suggesting that a combination of the three structures, including the nugget effect, is rudimentary for describing total spatial variation (Nanos et al. 2005; Bellier et al. 2007).

The PCs and RFs were mapped on a $0.5 \times 0.5 \mathrm{~km}$ rectangular grid using ordinary kriging (Eq. 1) and factorial co-kriging (Eq. 2) methods. Comparison of PC maps for CA (Fig. 5a,b) and RF maps for MFK at the regional scale (Fig. 6a,b) showed that low PC1 and high RF1 values occur along the boundaries of densely populated part of the city (Figs. 5a and 6a) whereas the PC2/RF2 maps (Figs. 5b, 6b) showed that the patterns were likely to be influenced by piedmont topology from both northern and southern sides. However, comparison of PC maps for PCA
(Fig. 5c,d) and RFs for MFK at the regional scale (Fig. 6c,d) revealed similarly complex patterns requiring further environmental interpretation.

Environmental interpretations

The DEM and NDVI were equally subdivided into ten categories according to their ranges. The tabulated area against DEM and NDVI indicated an NDVI of $-0.405-0.085$ and a DEM of $780-1,114 \mathrm{~m}$, each occupying $<5 \%$ of the total area. Consequently, these categories were excluded from environmental interpretations of ordination results (shaded areas in Figs. 7 and 8). Mapping results were plotted with mean values of PCs or RFs against categorized environmental variables (Figs. 7 and 8).

The $\mathrm{CA}$ results showed that the largest value of negative $\mathrm{PC} 1$ was observed in the land cover of suburban trees at a DEM of 112-222 $\mathrm{m}$ and NDVI of 0.447-0.554, and high PC2 values were observed in the land cover of suburban trees, forests, cultivated lands and meadows at DEM exceeding $112 \mathrm{~m}$ and NDVI above 0.447 (Fig. 7a,b,c). The conventional PCA results showed that the PC1 value was high for 


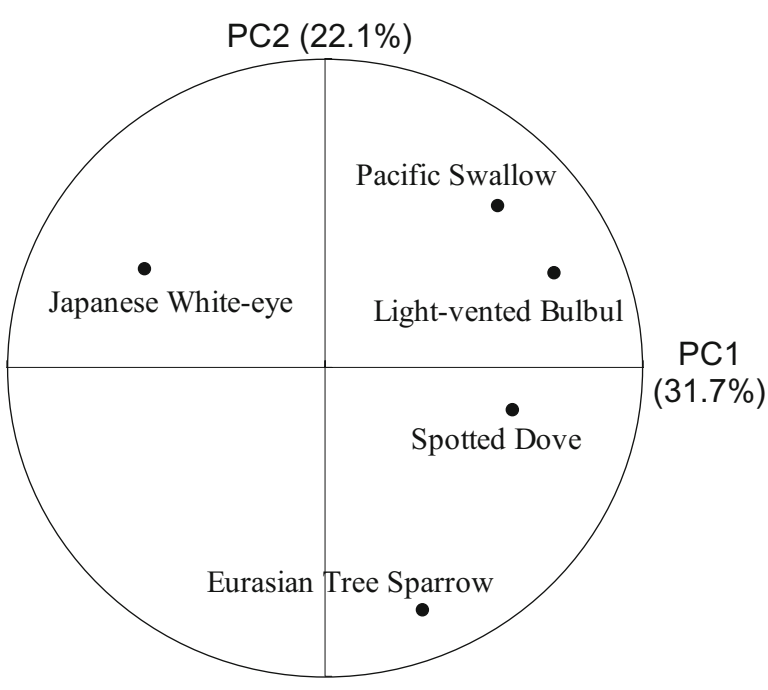

\section{a CA results}

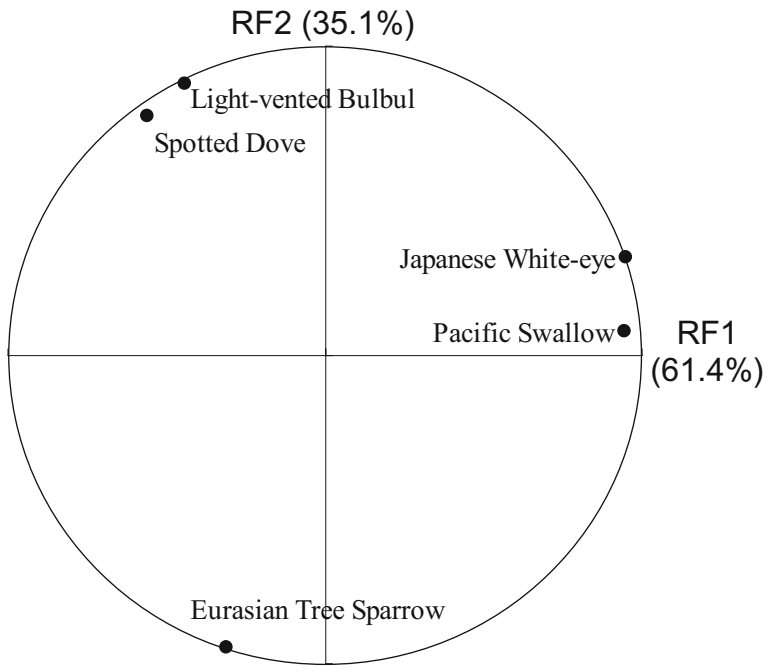

c MFK results at regional scale

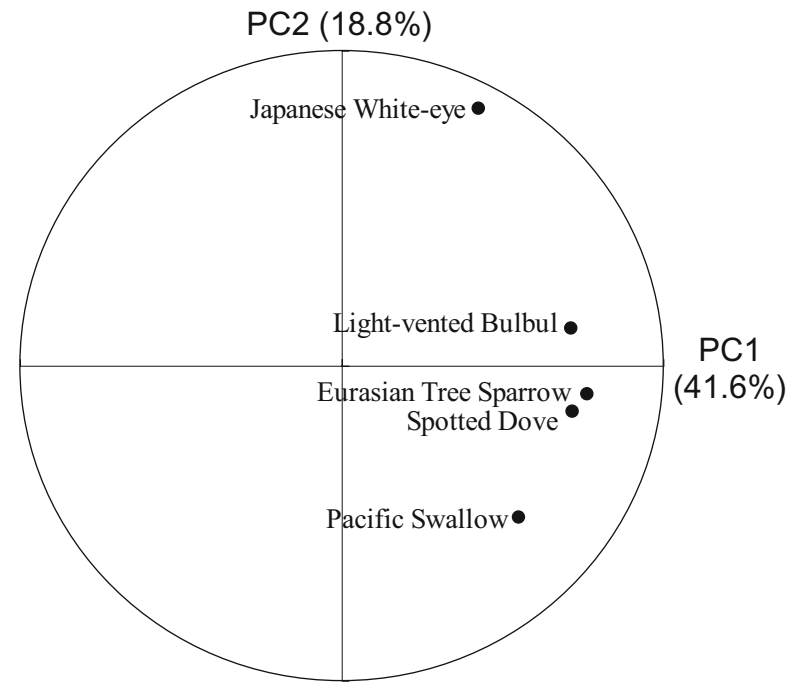

b conventional PCA results

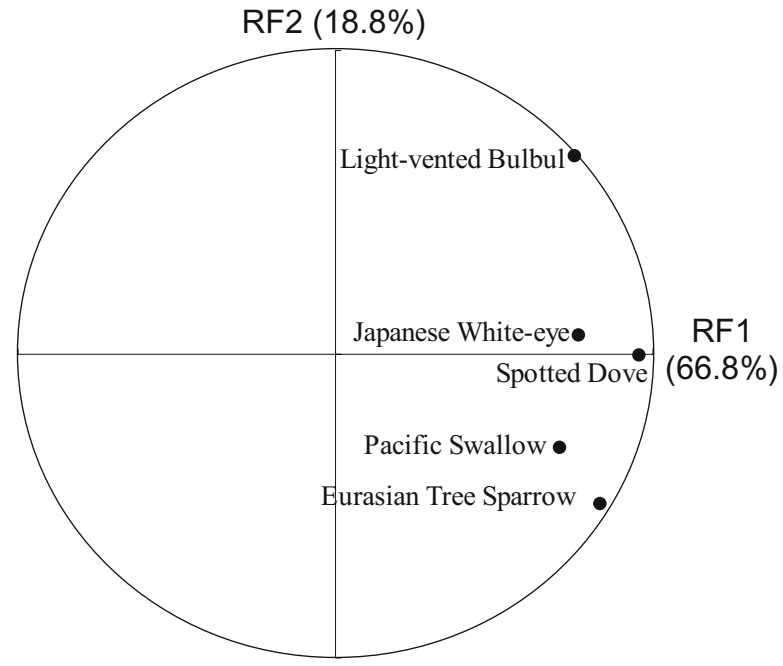

d MFK results at local scale

Fig. 4 The correlation circles determined by a CA, and $\mathbf{b}$ conventional PCA; the correlation circles determined by MFK at $\mathbf{c}$ the regional scale, and $\mathbf{d}$ the local scale

the land cover of meadows with zero value for PC1 at a DEM of 335-445 $\mathrm{m}$ and highest at an NDVI of $0.128-0.234$. The PC2 value was high for the land cover of urban meadows with the highest value for PC2 at a DEM of 112-222 $\mathrm{m}$ and high at an NDVI of $-0.085-0.21$ and $0.447-0.554$ (Fig. 7d,e,f).

At the regional scale, the MFK results showed that the RF1 value was high for the land cover of suburban trees with the highest value for RF1 at a DEM of $112-334 \mathrm{~m}$ and NDVI of $0.341-0.554$. The RF2 value was high for the land cover of forest, with a zero value for RF2 at a DEM of 112-222 m and NDVI of $0.447-0.554$ (Fig. 8a,b,c). At the local scale, the MFK results showed that RF1 value was high for the land cover of urban meadows, with the highest value for RF1 at a DEM of $0-111 \mathrm{~m}$ and NDVI of 
Fig. 5 The CA mapping results of a $\mathrm{PC} 1$, and b PC2; the PCA mapping results of $\mathbf{c} \mathrm{PC} 1$, and $\mathbf{d} \mathrm{PC} 2$
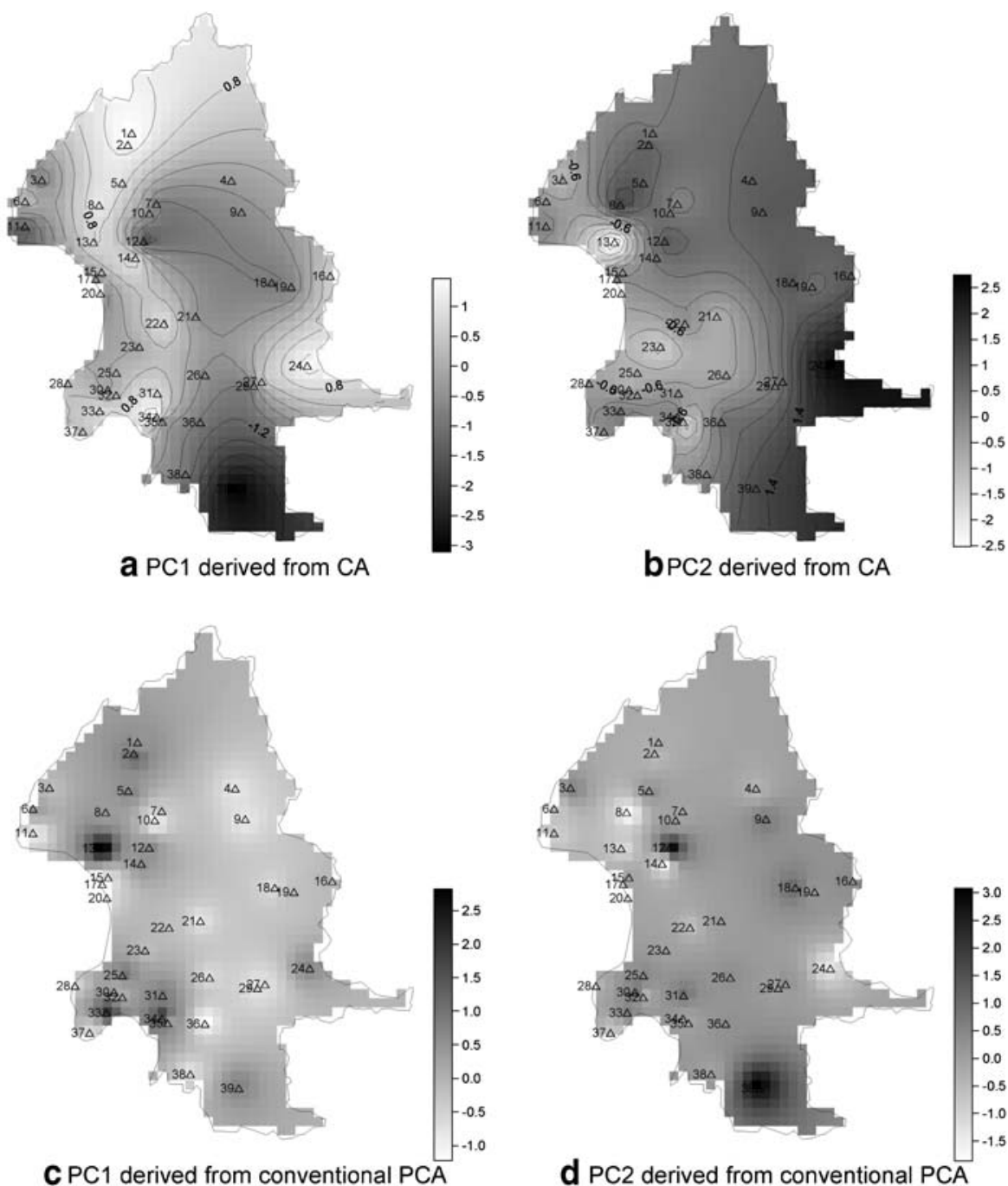

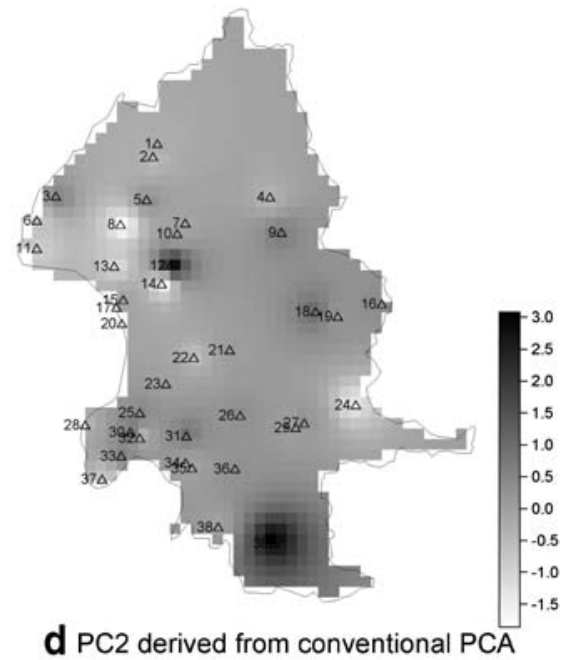

$0.128-0.234$. The RF2 value was highest for the land cover of meadows and highest at a DEM of 112-334 m and an NDVI of 0.447-0.554 (Fig. 8d,e,f).

\section{Discussion}

Comparison between conventional ordination methods and multivariate factorial kriging

Recent studies indicate that urban bird communities are influenced by complex combinations of environmental factors at different scales (Melles et al. 2003; Savard et al. 2000). In MFK, the different correlations between five species at different scales suggest that different species with different physiological habits and characteristics may have markedly unique responses to environmental change at multiple scales. Carroll and Pearson (1998) indicated that the geostatistical method is best suited for delineating largescale variations in species. The correlation circles and mapping results of conventional PCA are similar to those of MFK at the local scale while the CA results are similar to the MFK results at the regional scale. The analytical similarity is consistent with studies by ter Braak and Looman (1995) and Wagner (2004); CA is appropriate for modeling unimodal species distributions along a long environment gradient while PCA is best for modeling linear species distributions along a short environment gradient. The consistency also indicates that MFK, which can simultaneously analyze variations at multiple scales, can efficiently 
Fig. 6 The MFK mapping results of a RF1, and b RF2 at the regional scale; $\mathbf{c}$ RF1, and d RF2 at the local scale

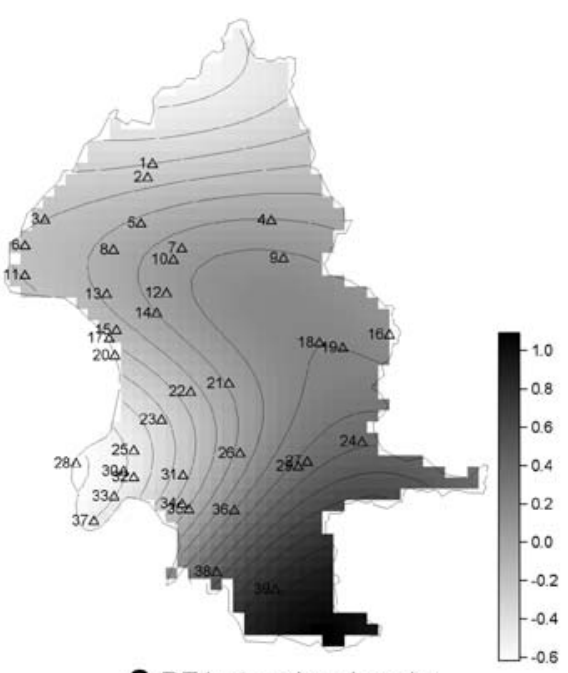

a RF1 at regional scale

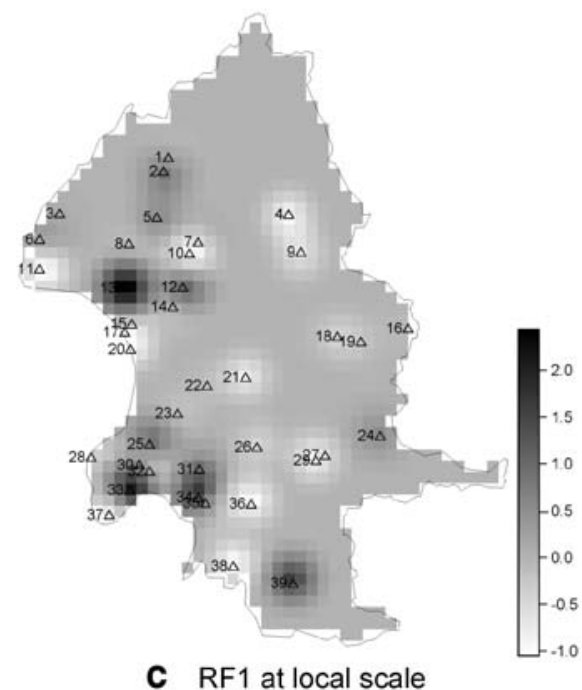

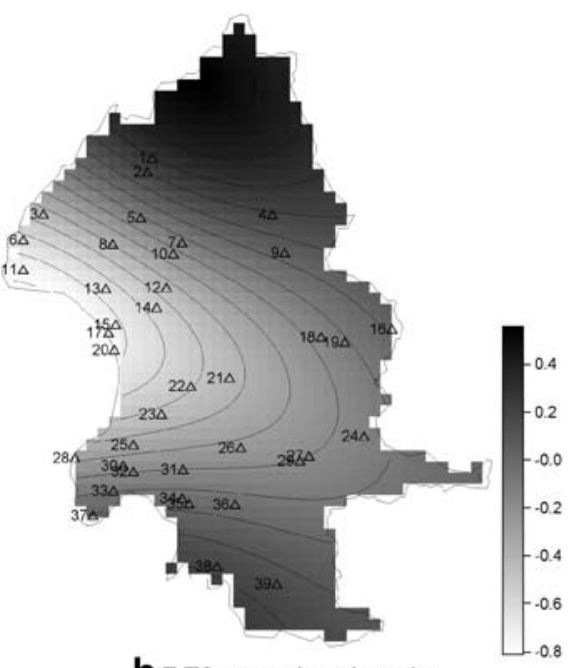

bRF2 at regional scale

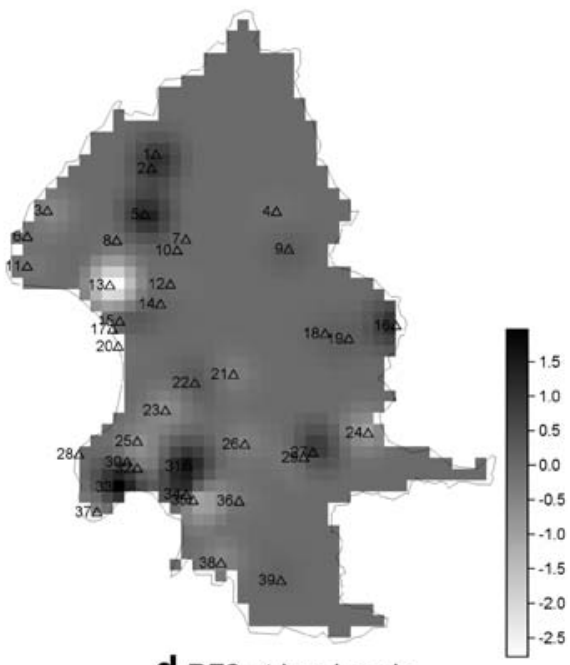

d RF2 at local scale extract spatial patterns for variations not only at scales as large as those of CA but can also delineate spatial patterns for variations at scales as small as those of conventional PCA.

Another advantage of using MFK instead of conventional ordination methods is that MFK can determine the variation proportions at multiple scales. The MFK results indicate that local-scale variation accounted for a larger proportion (59.5\%) of total variation in this study. Moreover, local-scale variation was affected more by determinate factors than by regional-scale variation. This analytical result is consistent with multi-scale studies indicating local factors are more important than regional factors in shaping urban bird communities (Jokimäki and Kaisanlahti-Jokimäki 2003). Further, a comparative summation of variation proportions extracted by the first two PCs/RFs factors of PCA (54\%), CA (60\%) and MFK $(97 \%$ at the regional scale and $86 \%$ at the local scale) demonstrate that conventional ordination methods are less efficient than MFK for extracting principal components. The multi-scale variography in MFK reduces the degree of freedom in statistics by considering spatial lags between sample sites. Given the advantages of MFK revealed in this section, the further discussions of environmental interpretations and physiological evidence supporting these interpretations are based only on MFK results. 


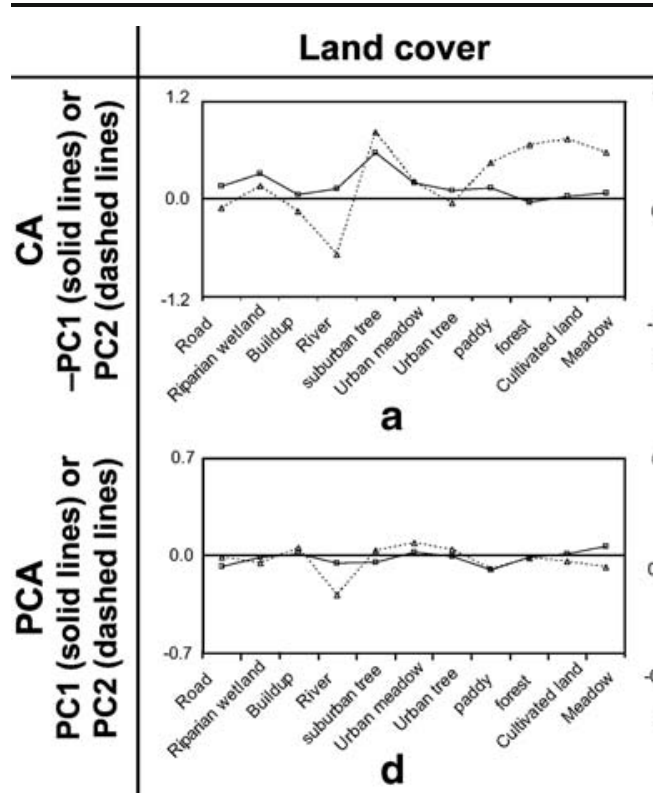

Fig. 7 Mean values of negative PC1 (solid lines) and PC2 (dashed lines) derived from CA against categorized a land cover, b DEM, and c NDVI; mean values of PC1 (solid lines)

Environmental interpretations

The environmental variables adopted for environmental interpretation should be literally acknowledged rather than an arbitrary choice. Environmental variables adopted in this study describe habitat heteroge-

\section{DEM}
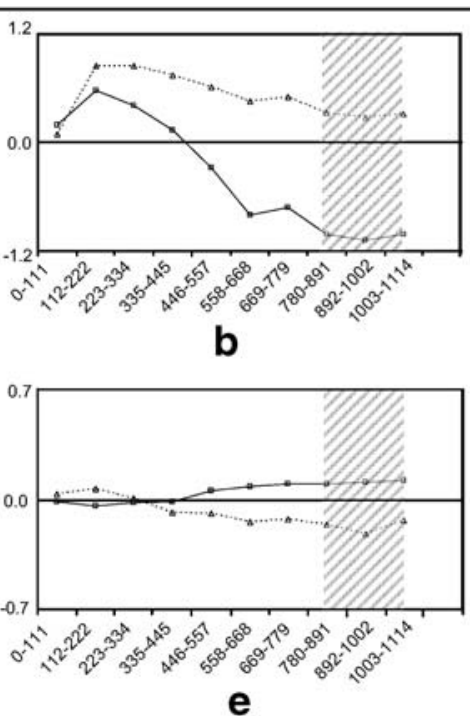
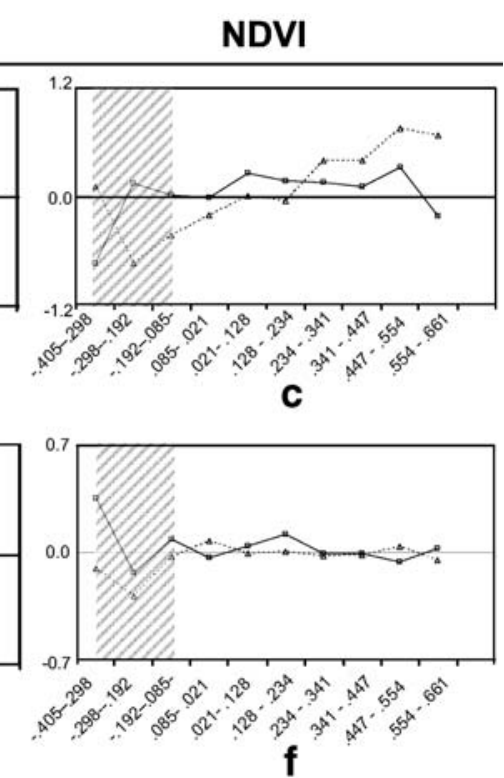

and PC2 (dashed lines) derived from conventional PCA against categorized $\mathbf{d}$ land cover, e DEM, and $\mathbf{f}$ NDVI. The shaded areas are excluded from the environmental interpretations

neity and primary conductivity that have been well investigated for their single-scale rather than multiscale influences on birds in Taiwan (Ding et al. 2005; Koh et al. 2006; Lee et al. 2004). The MFK indicated that species indeed respond differently to land-cover, DEM and NDVI at different scales.

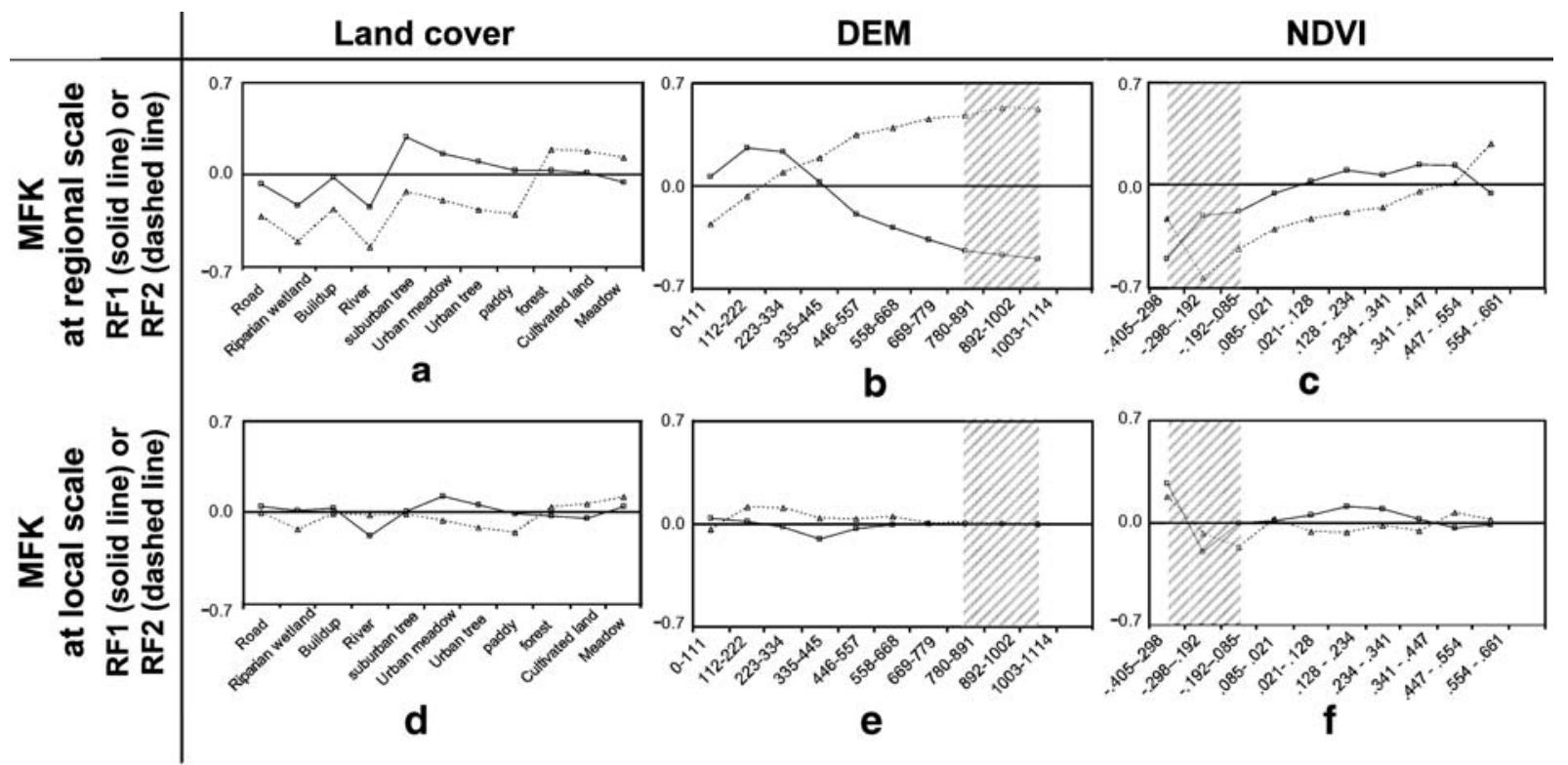

Fig. 8 Mean values of RF1 (solid lines) and RF2 (dashed lines) at the regional scale against categorized a land cover, b DEM, and c NDVI; mean values of RF1 (solid lines) and
RF2 (dashed lines) at the local scale against categorized $\mathbf{d}$ land cover, e DEM, and $\mathbf{f}$ NDVI. The shaded areas are excluded from the environmental interpretations 
Fig. 9 a The belt regions (black shaded) with positive mean value for RF1 at the regional scale, $\mathbf{b}$ the interface (grey shaded) between zones with positive mean value (black shaded) and negative mean value (white) for RF2 at the regional scale, $\mathbf{c}$ the regions (black shaded) with positive mean value for RF1 at the local scale, and $\mathbf{d}$ the belt regions (black shaded) with positive mean value for RF2 at the local scale
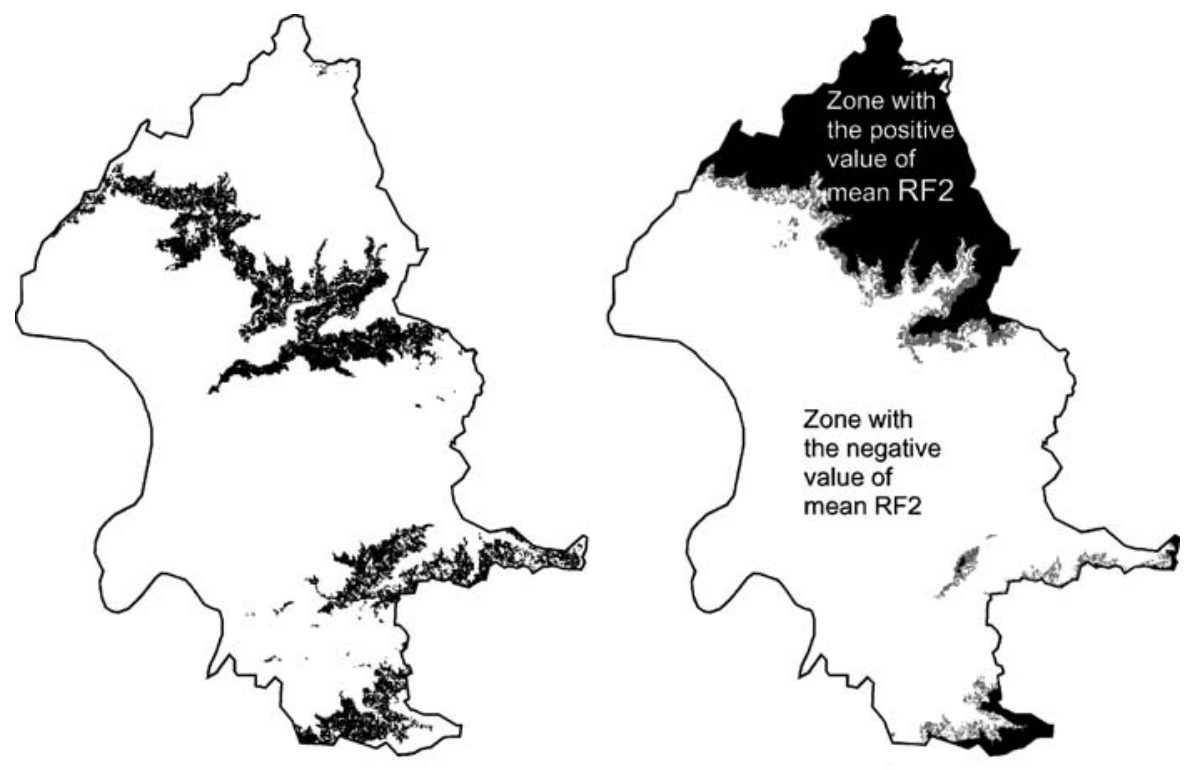

b
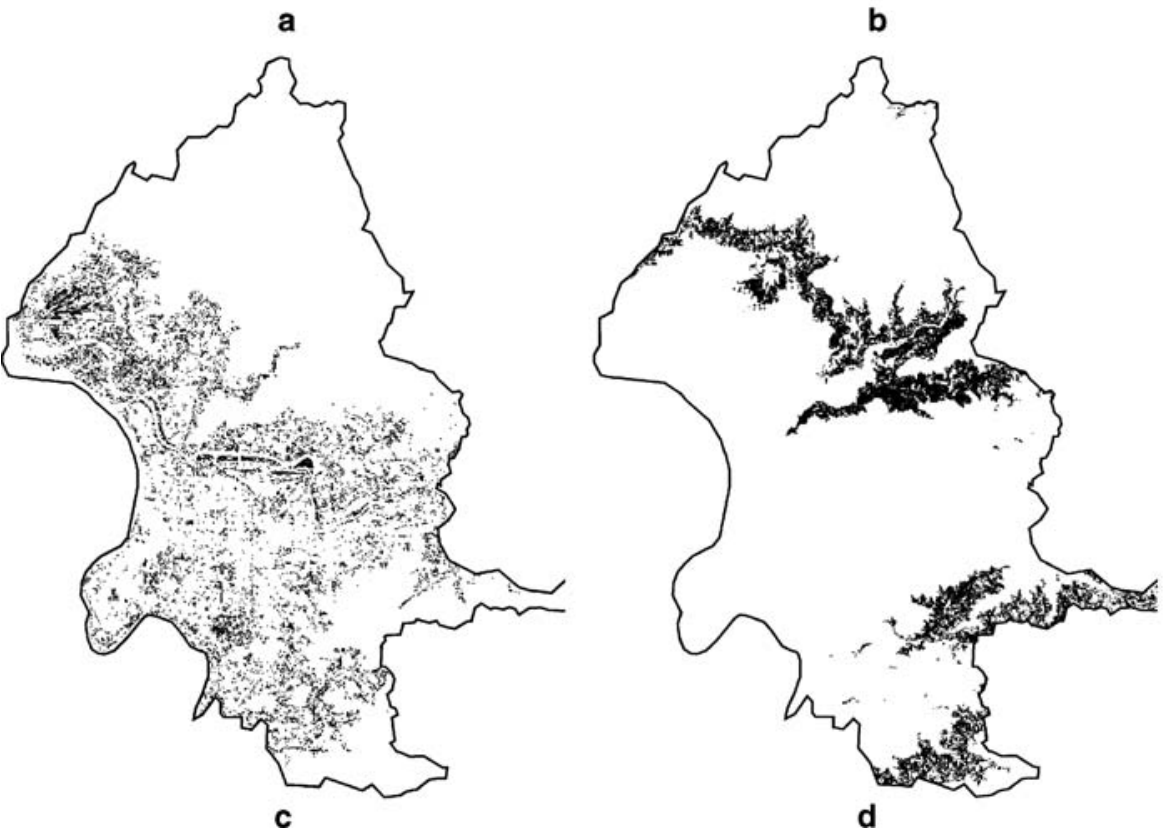

The ecotone between different plant taxa and the boundaries between different land covers may increase the number of birds at the high side of the primary productivity gradient than at the low side and in areas adjacent to open areas (Baker et al. 2002; Lahti 2001). McKinney (2006) also indicated that numerous exotic species migrate from areas surrounding fringe areas and take advantage of human-created habitats. These species are adapted to forest edges and surrounding open areas. According to environmental interpretations of RF1 at the regional scale derived from MFK, belt regions with a DEM of 112-334 m and NDVI of $0.341-0.554$ were mapped to identify locations exhibiting a high value (0.2544) of mean RF1 at the regional scale. Consequently, low values (0.0065) of mean RF1 at the regional scale occurred outside the belt regions (Fig. 9a). Based on environmental interpretations of RF2 at the local scale derived from MFK, the belt regions with a DEM of $112-334 \mathrm{~m}$ and NDVI of $0.447-0.554$ were also mapped to identify areas in which the positive value (0.0943) of the mean RF2 at the local scale was 
located. Consequently, the negative value $(-0.0102)$ of mean RF2 at the local scale extended beyond the belt regions (Fig. 9d). The belt regions were located at the interface between densely populated areas of the city and forest land cover. The land cover interpretations indicated that the mean RF1 value at the regional scale was high for suburban treed land whereas the mean RF2 at the local scale was high for meadowland. The positive RF1 at the regional scale and the positive RF2 at the local scale correlated with the suburbs, where transitions exist between natural and urban land covers.

Rahbek (1995) indicated that the monotonic decline in species richness with increasing elevation may not be a general pattern. Bird species richness has a hump-shaped relationship with elevation, which peaks at approximately 2,000 $\mathrm{m}$ in Taiwan (Koh et al. 2006; Lee et al. 2004). According to environmental interpretations of RF2 at the regional scale derived from MFK, the interface with a DEM of 112-222 m and NDVI of $0.447-0.554$ was mapped to locate the interface between zones with a negative value $(-0.2339)$ or a positive value $(0.2788)$ for mean RF2 (Fig. 9b). The environmental interpretations show that mean RF2 is monotonically correlated with increased elevation, and forestland has high mean RF2. The monotonically positive relationship between RF2 value at the regional scale and elevation implies that this relationship was derived for an elevation lower than $2,000 \mathrm{~m}$.

Many studies have underlined the importance of preserving green areas in urban landscapes to protect biodiversity (Pautasso 2007; Sodhi et al. 1999) and specialized forest species (Sandström et al. 2006). Azerrad and Nilson (2001), who utilized different types and formations of green land cover to investigate avian community characteristics in urban areas, found that species richness is highest in areas with meadow/lawn cover. According to environmental interpretations of RF1 at the local scale derived from MFK, regions with a DEM of 0-111 $\mathrm{m}$ and an NDVI of $0.128-0.234$ were mapped to identify areas with a high value $(0.1229)$ of mean RF1 at the local scale. Consequently, areas beyond mapped regions (Fig. 9c) have a low value (0.0019) for mean RF1 at the local scale. Land cover interpretations show that RF1 at the local scale is high for urban meadowland cover existing in densely populated part of the city. Moreover, the correlation circles indicate that the RF1 at the local scale accounts for the largest (39.7\%) total variation among all RFs at both scales (Fig. 4c,d).

Physiological evidences for environmental interpretations

Bolger (2001) argued that the region between urban land use and natural habitat engenders the potential for bottom-up effects. As indicated by Adams (1994) and McKinney (2006), suburban landscapes composed of forest stands and secure open nesting habitats meet the habitat needs of insectivorous and omnivorous avian species. Lim and Sodhi (2004) and McKinney (2006) also determined that frugivores commonly feed on fruit-bearing ornamental plants in suburban areas of tropical cities with low-density housing. Pacific Swallow and Japanese White-eye populations correlate with RF1 at the regional scale (Fig. 4c) while Light-vented Bulbul populations correlate with a positive RF2 at the local scale (Fig. 4d). Environmental interpretations indicate that a positive RF1 at the regional scale (Fig. 9a) and positive RF2 at the local scale (Fig. 9d) represent suburban regions. The Pacific Swallow is an aerial insectivore whereas the Japanese White-eye and Light-vented Bulbul are omnivores with frugivorous habits. Accordingly, increased populations of Japanese White-eye, Pacific Swallow and Light-vented Bulbul should correlate with suburban areas, as noted in this study.

Lim and Sodhi (2004) indicated that abundance of granivores increases as public housing increases, probably because these areas contain anthropogenic food sources. The Eurasian Tree Sparrow is correlated with a negative RF2 at the regional scale (Fig. 4c) and a positive RF1 at the local scale (Fig. 4d). Environmental interpretations suggest that the negative RF2 at the regional scale (the zone with the negative mean RF2, as shown in Fig. 9b) and the positive RF1 at the local scale (Fig 9c) represent the densely populated part of the city. The Eurasian Tree Sparrow is an omnivore with granivorous habits. Consequently, the Eurasian Tree Sparrow should be correlated with the densely populated urban areas, as noted in this study.

Numerous studies have suggested that birds with large body sizes are associated with habitats with considerable resource availability (Ding et al. 2005; 
Winter et al. 2006). Although attracted to human waste, large species are less tolerant of humans than small species (Campbell 2006). This study revealed that, since lowland areas are the most densely populated urban areas, NDVI increases as elevation increases. Environmental interpretations show that RF2 at the regional scale increases with increasing elevation (Fig. 9b). The correlation circles obtained from MFK indicate that RF2 at the regional scale positively affects populations of Spotted Dove and Light-vented Bulbul and negatively affects populations of Eurasian Tree Sparrow (Fig. 4c). Notably, the Spotted Dove and Light-vented Bulbul are larger than the other three species. Therefore, the positive correlations between the Spotted Dove and Lightvented Bulbul and increasing elevations may be related to the large body sizes of the two birds.

Implication of MFK in conservation

Savard et al. (2000) emphasized the need for a multiscale approach to addressing biodiversity questions and also illustrated the action needed to preserve or enhance biodiversity at multiple scales. The MFK is an efficient tool for bird conservation at multiple scales because MFK delineates hotspots of spatial variations at multiple scales, which facilitates identification of potential locations for habitat preservation at different scales and suggests groups that may respond similarly to management actions. Among various environmental measures, the use of landcover zoning in conservation efforts can be beneficial at a local scale in the form of regulating land-cover near areas of particular importance to birds and at a regional scale by maintaining adequate proportions of specific land-cover (Turner 2003).

Sandström et al. (2006) concluded that a new residential development in a city should be interspersed with sufficient amount and quality of green space to protect, maintain and restore functional green infrastructures in urban landscapes. The map of RF2 at the regional scale shows high RF2 values in the northern mountains of Yangmingshan National Park. Wildlife management strategy should focus on preventing exploitation of this forest area because of its importance in supporting species variation (Fig. 9b). Pino et al. (2000) indicated that the peri-metropolitan area composed of semi-natural and agricultural landscapes have both local and regional influences on increasing bird populations, not only due to habitat changes within the same area but also due to interactive effects of adjacent or separate regions. The local scale RF1 map shows the lowest RF1 values occur in the center of densely populated areas of Taipei City. Urban planning should allocate more meadowlands to this area to strengthen the connectivity between existing meadowlands because the land-cover interpretation shows a strong correlation between urban meadows and variation in bird species (Fig. 9c). Areas with high gradients of bird spatial variations in suburban areas of Taipei City (south and north parts) should be considered for designation as buffer zones to conserve suburban forests and meadows because suburban forests and meadows influence spatial variations in bird species at regional and local scales, respectively (Fig. 9a,d). Nevertheless, MFK can provide essential information for local and regional urban green space and network planning for bird conservation.

\section{Conclusions}

The spatially explicit multi-scale approach of multivariate factorial kriging reflects the local scale variation among species identified using conventional PCA and can further construct spatial correlations between species at the geographical scale identified using CA. The influence of scales can be simultaneously identified using MFK. In this study, MFK analysis indicated that existing urban meadowland cover in densely populated areas of Taipei City affects the five bird species within a range of $2 \mathrm{~km}$ whereas elevation heterogeneity affects these birds within a range of $16 \mathrm{~km}$. The suburban forest and meadowland in the belt region located in suburbs affect these birds within ranges of 16 and $2 \mathrm{~km}$, respectively. Environmental interpretations are further supported by considering the physiological habits and characteristics of the five bird species. The suburbs attract insectivores and omnivores with frugivorous habits whereas omnivores with granivorous habits adapt more readily to highly urbanized areas. The geographical influences of elevation heterogeneity on proliferation of bird species are likely explained by body size, except in the case of birds adapted to suburbs. Despite environmental change, the physiological characteristics of a bird species ultimately determine the extent 
to which they are impacted by environmental change. This study revealed that feeding habits and body size are possible determinants in delineating the spatial patterns of species. By using remote sensing data as environmental descriptors, this study analyzed commonly observed avian species by MFK to elucidate species-environment relationships. However, fieldintensive census data for rare species can also be used in future studies using the same methodology. The MFK not only provides simultaneous analysis of variations at multiple scales but also facilitates identification of locations and actions for local and regional bird conservation efforts.

Acknowledgements The authors would like to thank the National Science Council of Taiwan for financially supporting this research under Contract No. NSC 95-2313-B-041-002. The authors also extend their gratitude to Taiwan Wild Bird Federation for providing the field data.

\section{References}

Adams, L. W. (1994). Urban wildlife habitats: a landscape perspective. Minnesota: Minnesota University Press.

Aubry, P., \& Debouzie, D. (2001). Estimation of the mean from a two-dimensional sample: the geostatistical model-based approach. Ecology, 82, 1484-1494.

Azerrad, J. M., \& Nilson, C. H. (2001). Avian community characteristics of urban green spaces in St. Louis, Missouri. In J. M. Marzluff, R. Bowman, \& R. Donnelly (Eds.), Avian ecology and conservation in an urbanizing world (pp. 486-503). Norwell: Kluwer.

Bailey, S. A., Horner-Devine, M. C., Luck, G., Moore, L. A., Carney, K. M., Anderson, S., et al. (2004). Primary productivity and species richness: relationships among functional guilds, residency groups and vagility class at multiple spatial scales. Ecography, 27, 207-217.

Baker, J., French, K., \& Whelan, R. J. (2002). The edge effect and ecotonal species: bird communities across a natural edge in Southeastern Australia. Ecology, 83, 3048-3059.

Bellier, E., Monestiez, P., Durbec, J. P., \& Candau, J. N. (2007). Identifying spatial relationships at multiple scales: principal coordinates of neighbour matrices (PCNM) and geostatistical approaches. Ecography, 30, 385-399.

Bennett, A. F., Hinsley, S. A., Bellamy, P. E., Swetnam, R. D., $\&$ Mac Nally, R. (2004). Do regional gradients in land-use influence richness, composition and turnover of bird assemblages in small woods? Biological Conservation, 119, 191-206.

Bolger, D. T. (2001). Urban birds: population, community, and landscape approaches. In J. M. Marzluff, R. Bowman, \& R. Donnelly (Eds.), Avian ecology and conservation in an urbanizing world (pp. 155-177). Norwell: Kluwer.

Bourennane, H., Salvador-Blanes, S., Cornu, S., \& King, D. (2003). Scale of spatial dependence between chemical properties of topsoil and subsoil over a geologically contrasted area (Massif central, France). Geoderma, 112, 235-251.

Box, E. O., Holcen, B. N., \& Kalb, V. (1989). Accuracy of the AVHRR vegetation index as a predictor of biomass, primary productivity and net $\mathrm{CO} 2$ flux. Vegetatio, 80, 71-89.

Brennan, S. P., \& Schnell, G. D. (2005). Relationship between bird abundances and landscape characteristics: the influence of scale. Environmental Monitoring and Assessment, 105, 209-228.

Campbell, M. O. (2006). Urban parks as shared spaces? The utility of alert distances as indicators of avian tolerance of humans in Stirling Scotland. Area, 38, 301-311.

Carroll, S. S., \& Pearson, D. L. (1998). The effects of scale and sample size on the accuracy of spatial predictions of tiger beetle (Cicindelidae) species richness. Ecography, 21, 401-414.

Castrignanò, A., Giugliarini, L., Risaliti, R., \& Martinelli, N. (2000). Study of spatial relationships among some soil physica-chemical properties of a field in central Italy using multivariate geostatistics. Geoderma, 97, 39-60.

Chang, W. F. (1985). A field guide to the birds of Taiwan. Taiwan: Bird Image Publication (in Chinese).

Chase, M. K., Kristan, W. B., Lynam, A. J., Price, M. V., \& Rotenberry, J. T. (2000). Single species as indicators of species richness and composition in California coastal sage scrub birds and small mammals. Conservation Biology, 14, 474-487.

Couteron, P., \& Ollier, S. (2005). A generalized, variogram-based framework for multi-scale ordination. Ecology, 86, 828-834.

Cressie, N. (1990). The origins of kriging. Mathematical Geology, 22, 239-252.

Cushman, S. A., \& McGarigal, K. (2004). Hierarchical analysis of forest bird species-environment relationships in the Oregon Coast Range. Ecological Applications, 14, 1090-1105.

Dale, M. R. T., Dixon, P., Fortin, M. J., Legendre, P., Myers, D. E., \& Rosenberg, M. S. (2002). Conceptual and mathematical relationships among methods for spatial analysis. Ecography, $25,558-577$.

Debinski, D. M., Kindscher, K., \& Jakubauskasa, M. E. (1999). A remote sensing and GID-based model of habitats and biodiversity in the Great Yellowstone Ecosystem. International Journal of Remote Sensing, 20, 3281-3291.

Ding, T. S., Yuan, H. W., Geng, S., Lin, Y. S., \& Lee, P. F. (2005). Energy flux, body size and density in relation to bird species richness along an elevational gradient in Taiwan. Global Ecology and Biogeography, 14, 299-306.

Diniz-Filho, J. A. F., \& Bini, L. M. (2005). Modeling geographical patterns in species richness using eigenvectorbased spatial filters. Global Ecology and Biogeography, 14, $77-185$.

Diniz-Filho, J. A. F., Bini, L. M., \& Hawkins, B. A. (2003). Spatial autocorrelation and red herrings in geographical ecology. Global Ecology and Biogeography, 12, 53-64.

Drapeau, P., Leduc, A., Giroux, J. F., Savard, J. P. L., Bergeron, Y., \& Vickery, W. L. (2000). Landscape-scale disturbances and changes in bird communities of boreal mixed-wood forests. Ecological Monographs, 70, 423-444.

Dungan, J. L., Perry, J. N., Dale, M. R. T., Legendre, P., CitronPousty, S., Fortin, M. J., et al. (2002). A balanced view of scale in spatial statistical analysis. Ecography, 25, 626640 . 
Fang, W. H., Feng, S., \& Wang, J. D. (2005). The illustrated handbook for urban birding. Taipei: Owl Publishing Co (in Chinese).

Fernández-Juricic, E. (2002). Nested patterns of species distribution and winter flock occurrence of insectivorous birds in a fragmented landscape. Ecoscience, 9, 450-458.

Fortin, M. J. (1999). Spatial statistics in landscape ecology. In J. M. Marzluff, R. Bowman, \& R. Donnelly (Eds.), Avian ecology and conservation in an urbanizing world (pp. 253-279). Norwell: Kluwer.

Githaiga-Mwicigi, J. M. W., Fairbanks, D. H. K., \& Midgley, G. (2002). Hierarchical processes define spatial pattern of avian assemblages restricted and endemic to the arid Karoo, South Africa. Journal of Biogeography, 29, 10671087.

Goovaerts, P. (1997). Geostatistics for natural resources evaluation. New York: Oxford University Press.

Goovaerts, P., Jacquez, G. M., \& Marcus, A. (2005). Geostatistical and local cluster analysis of high resolution hyperspectral imagery for detection of anomalies. Remote Sensing of Environment, 95, 351-367.

Goulard, M., \& Voltz, M. (1992). Linear co-regionalization model: tools for estimation and choice of cross-variogram matrix. Mathematical Geology, 24, 269-286.

Grossman, G. D., Nickerson, D. M., \& Freeman, M. C. (1991). Principal component analysis of assemblage structure data utility of tests based on eigenvalues. Ecology, 72, 341-347.

Hostetler, M. (1999). Scale, birds, and human decisions: a potential for integrative research in urban ecosystems. Landscape and Urban Planning, 45, 15-19.

Hostetler, M., \& Holling, C. S. (2000). Detecting the scales at which birds respond to structure in urban landscapes. Urban Ecosystems, 4, 25-54.

Jensen, T. R. (1996). Introductory digital image processing: a remote sensing perspective. Upper Saddle River, NJ: Prentice-Hall.

Jokimäki, J., \& Kaisanlahti-Jokimäki, M. L. (2003). Spatial similarity of urban bird communities: a multiscale approach. Journal of Biogeography, 30, 1183-1193.

Koh, C. N., Lee, P. F., \& Lin, R. S. (2006). Bird species richness patterns of northern Taiwan: primary productivity, human population density, and habitat heterogeneity. Diversity and Distributions, 12, 546-554.

Kuo, W. S., \& Young, C. Y. (1981). Division of agricultureclimate zone in Taiwan area. Meteorological Bulletin, 27, 16-28 (in Chinese).

Lahti, D. C. (2001). The "edge effect on nest predation" hypothesis after twenty years. Biological Conservation, 99, 365-374.

Lee, P. F., Ding, T. S., Hsu, F. H., \& Geng, S. (2004). Breeding bird species richness in Taiwan: distribution on gradients of elevation, primary productivity and urbanization. Journal of Biogeography, 31, 307-314.

Legendre, P., \& Fortin, M. J. (1989). Spatial pattern and ecological analysis. Vegetatio, 80, 107-138.

Legendre, P., \& Legendre, L. (1998). Numerical ecology. Amsterdam: Elsevier Science.

Leica Geosystems (2003). ERDAS IMAGINE tour guides: version 8.7. Atlanta: Leica Geosystems GIS and Mapping.

Levin, S. A. (1992). The problem of pattern and scale in ecology. Ecology, 73, 1943-1976.
Lim, H. C., \& Sodhi, N. S. (2004). Responses of avian guilds to urbanization in a tropical city. Landscape and Urban Planning, 66, 199-215.

Lin, Y. P. (2002). Multivariate geostatistical methods to identify and map spatial variations of soil heavy metals. Environmental Geology, 42, 1-10.

Lin, Y. B., Lin, Y. P., Liu, C. W., \& Tan, Y. C. (2006). Mapping of spatial multi-scale sources of arsenic variation in groundwater on ChiaNan floodplain of Taiwan. Science of the Total Environment, 370, 168-181.

Lin, Y. B., Tan, Y. C., Lin, Y. P., Liu, C. W., \& Hung, C. J. (2004). Geostatistical method to delineate anomalies of multi-scale spatial variation in hydrogeological changes due to the ChiChi earthquake in the ChouShui river alluvial fan in Taiwan. Environmental Geology, 47, 102118.

Lin, Y. P., Yeh, M. S., Deng, D. P., \& Wang, Y. C. (2007). Geostatistical approaches and optimal additional sampling schemes for spatial patterns and future samplings of bird diversity in the Taipei Basin, Taiwan. Global Ecology and Biogeography, DOI 10.1111/j.1466-8238.2007.00352.x.

Luoto, M., Kuussaari, M., \& Toivonen, T. (2002). Modelling butterfly distribution based on remote sensing data. Journal of Biogeography, 29, 1027-1037.

Maestre, F. T. (2005). Spatial associations and patterns of perennial vegetation in a semiarid steppe: a multivariate geostatistics approach. Plant Ecology, 179, 133-147.

Marzluff, J. M., Bowman, R., \& Donnelly, R. (2001). A historical perspective on bird research: trends, terms, and approaches. In J. M. Marzluff, R. Bowman, \& R. Donnelly (Eds.), Avian ecology and conservation in an urbanizing world (pp. 1-17). Norwell: Kluwer.

McKinney, M. L. (2006). Urbanization as a major cause of biotic homogenization. Biological Conservation, 27, 247-260.

Melles, S., Glenn, S., \& Martin, K. (2003). Urban bird diversity and landscape complexity: species-environment associations along multiscale habitat gradient. Conservation Ecology, 7, Art. No. 5.

Nanos, N., Pardo, F., Nager, J. A., Pardos, J. A., \& Gil, L. (2005). Using multivariate factorial kriging for multiscale ordination: a case study. Canadian Journal of Forester Research, 35, 2860-2874.

Pannatier, Y. (1996). VARIOWIN: Software for spatial data analysis in 2D: version 2.2. New York: Springer-Verlag.

Pautasso, M. (2007). Scale dependence of the correlation between human population presence and vertebrate and plant species richness. Ecology Letters, 10, 16-24.

Pettorelli, N., Vik, J. O., Mysterud, A., Gaiilard, J. M., Tucker, C. J., \& Stenseth, N. C. (2005). Using the satellite-derived NDVI to assess ecological responses to environmental change. Trends in Ecology \& Evolution, 20, 503-510.

Pino, J., Roda, F., Ribas, J., \& Pons, X. (2000). Landscape structure and bird species richness: implications for conservation in rural areas between natural parks. Landscape and Urban Planning, 49, 35-48.

Rahbek, C. (1995). The elevation gradient of species richness: a uniform pattern? Ecography, 18, 200-205.

Reis, A. P., Sousa, A. J., \& Fonseca, E. C. (2003). Application of geostatistical methods in gold geochemical anomalies identification (Montemor-O-Novo, Portugal). Journal of Geochemical Exploration, 77, 45-63. 
Sandström, U. G., Angelstam, P., \& Mikusiński, G. (2006). Ecological diversity of birds in relation to the structure of urban green space. Landscape and Urban Planning, 77, 39-53.

Savard, J. P. L., Clergeau, P., \& Mennechez, G. (2000). Biodiversity concepts and urban ecosystems. Landscape and Urban Planning, 48, 131-142.

Sodhi, N. S., Briffett, C., Kong, L., \& Yuen, B. (1999). Bird use of linear areas of a tropical city: implications for park connector design and management. Landscape and Urban Planning, 45, 123-130.

ter Braak, C. J. F., \& Looman, C. W. N. (1995). Regression. In R. H. G. Jongaman, C. J. F. ter Braak, \& O. F. R. van Tongeren (Eds.), Data analysis in community and landscape ecology (pp. 29-77). Cambridge: Cambridge University Press.

Thogmartin, W. E., Sauer, J. R., \& Knutson, M. G. (2004). A hierarchical spatial model of avian abundance with application to Cerulean Warblers. Ecological Applications, 14, 17661779.

Tucker, C. J., Vanpraet, C. L., Sharman, M. J., \& van Ittersum, G. (1985). Satellite remote sensing of total herbaceous biomass production in the Senegalese Sahel: 1980-1984. Remote Sensing of Environment, 17, 233-249.

Turner, W. R. (2003). Citywide biological monitoring as a tool for ecology and conservation in urban landscapes: the case of the Tucson Bird Count. Landscape and Urban Planning, 65, 149-166.
Turner, M. G., Gardner, R. H., O, , \& O’Neill, R. V. (2001). Landscape ecology in theory and practice. New York: Springer-Verlag.

ver Hoef, J. M., \& Genn-Lewin, D. C. (1989). Multiscale ordination: a method for detecting pattern at several scales. Vegetatio, 82, 59-67.

Viedma, O., Melia, J., Segarra, D., \& GarciaHaro, J. (1997). Modeling rates of ecosystem recovery after fires by using Landsat TM data. Remote Sensing of Environment, 61, 383-398.

Wagner, H. H. (2004). Direct multi-scale ordination with canonical correspondence analysis. Ecology, 85, 342-351.

Wagner, H. H., \& Fortin, M. J. (2005). Spatial analysis of landscapes: concepts and statistics. Ecology, 86, 19751987.

Wiens, J. A. (1989). The ecology of bird communities: processes and variations, Vol. 2. New York: Cambridge University Press.

Wiens, J. A., Van Horne, B., \& Noon, B. R. (2002). Integrating landscape structure and scale into natural resource management. In J. Liu \& W. W. Taylor (Eds.), Integrating landscape ecology into natural resource management (pp. 23-67). Cambridge: Cambridge University Press.

Winter, M., Johnson, D. H., \& Shaffer, A. (2006). Does body size affect a bird's sensitivity to patch size and landscape structure. Condor, 108, 808-816. 